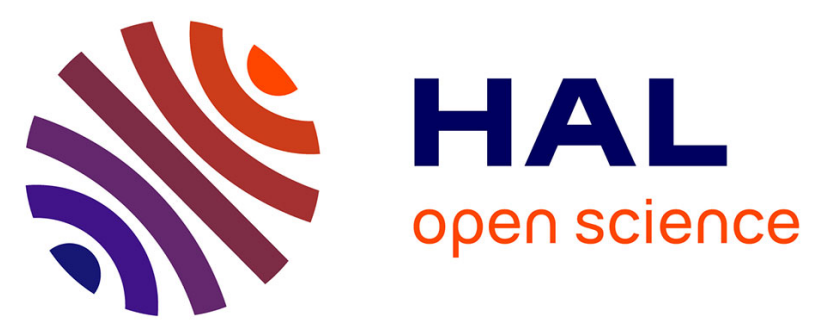

\title{
Assessment of the Perturbed Chain-Statistical Associating Fluid Theory Equation of State against a Benchmark Database of High-Quality Binary-System Data
}

Ilias Nikolaidis, Romain Privat, Jean-Noël Jaubert, Ioannis Economou

\section{To cite this version:}

Ilias Nikolaidis, Romain Privat, Jean-Noël Jaubert, Ioannis Economou. Assessment of the Perturbed Chain-Statistical Associating Fluid Theory Equation of State against a Benchmark Database of HighQuality Binary-System Data. Industrial and engineering chemistry research, 2021, 60 (24), pp.89358946. 10.1021/acs.iecr.1c01234 . hal-03324894

\section{HAL Id: hal-03324894 \\ https://hal.univ-lorraine.fr/hal-03324894}

Submitted on 24 Aug 2021

HAL is a multi-disciplinary open access archive for the deposit and dissemination of scientific research documents, whether they are published or not. The documents may come from teaching and research institutions in France or abroad, or from public or private research centers.
L'archive ouverte pluridisciplinaire HAL, est destinée au dépôt et à la diffusion de documents scientifiques de niveau recherche, publiés ou non, émanant des établissements d'enseignement et de recherche français ou étrangers, des laboratoires publics ou privés.

\section{(1) (1) $\$$}

Distributed under a Creative Commons Attribution - NonCommercial - NoDerivatives 44.0 


\section{Assessment of the Perturbed Chain-Statistical Associating Fluid Theory Equation of State against a Benchmark Database of High- Quality Binary-System Data}

Ilias K. Nikolaidis, Romain Privat, Jean-Noël Jaubert,* and Ioannis G. Economou*

Cite This: Ind. Eng. Chem. Res. 2021, 60, 8935-8946

Read Online

ACCESS 1

山l Metrics \& More

回 Article Recommendations

S1 Supporting Information

ABSTRACT: The perturbed chain-statistical associating fluid theory (PC-SAFT) equation of state $(\mathrm{EoS})$ is applied, and its performance is assessed using a reliable free-to-access benchmark thermodynamic database developed by the authors. A total of 200 nonelectrolytic binary systems are included in the database, which are divided into nine groups according to the associating character of the components, that is, their ability to be involved in a hydrogen bond. The properties based on which the assessment is performed include twophase vapor-liquid and liquid-liquid equilibrium, three-phase vapor-liquid-liquid equilibrium, critical point, azeotropic point, enthalpy of mixing, and heat capacity of mixing data. A specific procedure for the calculation of deviations between model predictions and experimental data and for grading the thermodynamic model is applied based on a previously published proposed methodology. The PC-SAFT EoS is implemented with classical mixing rules, no induced association scheme, and no regressed binary interaction parameters. The results are discussed, and specific characteristics of model performance with respect to different families of mixtures are analyzed.

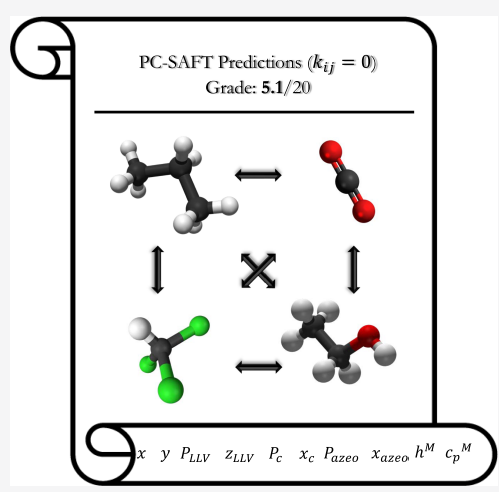

\section{INTRODUCTION}

Computer-aided process design has become in recent years the standard method for the preliminary and detailed design, simulation, and optimization of chemical processes. Knowing accurately the conditions of phase equilibrium as well as the physical properties of the chemical system(s) involved is the cornerstone of meaningful calculations for unit operations, sizing of the equipment, and capital and operational cost estimation.

Equations of state (EoS) have evolved rapidly in the last 20 years and have become the preferred choice for the calculation of physical properties and phase equilibria of mixtures. Their ability to predict or correlate the properties of all coexisting or individual fluid phases as well as the straightforward extension from pure components to mixture calculations significantly contributed to their establishment as a key tool. Furthermore, many models have been developed for the calculation of transport properties (viscosity, diffusivity, and thermal conductivity), which require parameters that can be conveniently provided by an accurate EoS. ${ }^{1-4}$ Finally, more sophisticated EoS models with a strong theoretical basis are being continuously developed, while a lot of effort is put on the improvement of existing ones.

The adoption rate of new models from the industry is rather low because the already implemented ones are only updated or replaced if the advantages of new models are very clear-cut. ${ }^{5-7}$ This slow transition of models from academic development to industrial application can be attributed to many factors, but the absence of validation against accurate experimental data that cover a wide range of compositions, temperatures, and pressures seems to be the major obstacle. ${ }^{8}$

A contribution toward addressing the relevant issue of model reliability has been made recently by Jaubert and co-workers. ${ }^{8} \mathrm{~A}$ high-quality reference database was built that can be used for evaluating the accuracy of an EoS (or any other model) or to directly compare the performances of different thermodynamic models. In total, 200 binary mixtures (no electrolytes are included) were selected to cover all types of systems and were categorized into nine groups (characterized by the binary association codes, BACs). The various groups are differentiated according to the associating character of the components included, that is, to their tendency to form a hydrogen bond. In brief:

- The category $\mathrm{BAC}_{1}-\mathrm{BAC}_{4}$ describes binary systems that do not show association.

- The group $\mathrm{BAC}_{5}$ is related to systems that exhibit selfassociation (tends to be broken by dilution effect).

Received: March 30, 2021

Revised: May 28, 2021

Accepted: May 28, 2021

Published: June 9, 2021

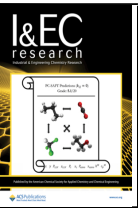


Table 1. Overview of the MAPEs between Experimental Data and Model Predictions (PC-SAFT EoS with vdW1f Mixing Rules and no BIPs) for the 200 Binary Systems Included in the Benchmark Database Proposed by Jaubert Et al. ${ }^{8 a, b}$

\begin{tabular}{|c|c|c|c|c|c|c|c|c|c|c|c|}
\hline \multirow[b]{2}{*}{ BAC } & \multirow[b]{2}{*}{ type of association } & \multicolumn{10}{|c|}{ MAPE on } \\
\hline & & $x$ & $y$ & $P_{\text {LLV }}$ & $z_{\mathrm{LLV}}$ & $P_{c}$ & $x_{c}$ & $P_{\text {azeo }}$ & $x_{\text {azeo }}$ & $h^{M}$ & $c_{p}{ }^{M}$ \\
\hline 1 (NA-NA) & & 14.5 & 11.3 & 4.2 & 367.7 & 6.5 & 36.1 & 5.2 & 167.5 & 62.8 & 190.3 \\
\hline 2 (HA-NA) & & 57.3 & 27.0 & & & 16.3 & 40.1 & - & - & 71.0 & 135.0 \\
\hline 3 (HD-NA) & no association & 66.4 & 35.0 & & & 10.3 & 36.0 & 15.2 & 39.3 & 78.4 & 184.4 \\
\hline $\begin{array}{l}4 \text { (HA-HA or } \\
\text { HD-HD) }\end{array}$ & & 32.9 & 24.0 & & & 19.0 & 42.1 & - & - & 49.8 & 95.7 \\
\hline 5 (SA-NA) & $\begin{array}{l}\text { mixtures in which self-association tends to be } \\
\text { broken }\end{array}$ & 66.7 & 21.9 & 3.1 & 1017.3 & 47.4 & 131.4 & 8.9 & 18.7 & 45.4 & 56.0 \\
\hline 6 (HD-HA) & $\begin{array}{l}\text { mixtures in which cross-association takes place } \\
\text { alone }\end{array}$ & 52.3 & 43.7 & & & 17.2 & 43.5 & 25.9 & 61.0 & 80.0 & 200.0 \\
\hline 7 (SA-HD) & & 36.9 & 19.8 & & & & & 6.1 & 20.9 & 63.4 & 171.3 \\
\hline 8 (SA-HA) & $\begin{array}{l}\text { mixtures in which both self-association and cross- } \\
\text { association take place }\end{array}$ & 58.9 & 31.6 & 19.1 & 47.2 & 40.6 & 57.5 & 20.7 & 49.5 & 53.5 & 81.2 \\
\hline 9 (SA-SA) & & 46.5 & 30.4 & - & - & 97.6 & 58.7 & 3.5 & 29.8 & 67.3 & 128.7 \\
\hline
\end{tabular}

${ }^{a_{T}}$ The mixtures are classified in nine BACs as proposed by Jaubert et al. ${ }^{8}{ }^{b} \mathrm{MAPE}=\frac{100}{\mathrm{NP}} \sum_{i=1}^{\mathrm{NP}}\left|\frac{P_{i}^{\text {calculated }}-P_{i}^{\text {experimental }}}{P_{i}^{\text {experimental }}}\right|$, where $\mathrm{NP}$ is the number of experimental data points and $P_{i}$ is the respective property. The abbreviations used for the associating character of a pure compound are: NA for "Non-Associating," HA for "Hydrogen-Acceptor", HD for "Hydrogen-Donor", and SA for "Self-Associating." Blanks indicate that no experimental data are available in the database for the respective properties, while dashes indicate that all calculations are deemed "out of model."

- The group $\mathrm{BAC}_{6}$ contains systems in which the only association effect is due to cross-association.

- The category $\mathrm{BAC}_{7}-\mathrm{BAC}_{9}$ is for systems that exhibit both cross-association and self-association.

A specific procedure for the calculation of the deviations between model calculations and experimental data was discussed in detail, and a methodology for grading a thermodynamic model was proposed. ${ }^{8}$ The properties based on which the assessment of a model is performed include twophase vapor-liquid (VLE) and liquid-liquid (LLE) equilibrium, three-phase vapor-liquid-liquid (VLLE) equilibrium, critical point, azeotropic point, enthalpy of mixing, and heat capacity of mixing data.

Jaubert and co-workers ${ }^{8}$ proposed to calculate the mean average percentage errors (MAPEs) between model calculations and experimental data for each of the 10 properties included in the database, as shown in Table 1 . The specified properties for the evaluation of the MAPEs are discussed in detail by Jaubert et $\mathrm{al}^{8}$ and a brief description is given in Section 2.1 of this work as well, including the algorithms and platform adopted. The target is to utilize the calculated MAPEs to give a mark (out of 20) to the thermodynamic model adopted, so that its accuracy can be evaluated and compared directly against that of other models. A mark equal to 20 is the highest attainable, and it can be achieved only if the model can reproduce exactly (with $0 \%$ MAPE) the entire number of experimental data available in the database. In every other case, a score lower than 20 will be given to the model. After the calculation of the MAPEs, the grading of the model starts by giving a mark over 20 to each of the nine BACs. This mark is the average of 10 marks, one for each of the 10 properties calculated. At this stage, the thermodynamic model is represented by nine marks (one for each BAC). Then, their number is reduced from 9 to 4 by grouping the marks obtained by similar BACs to finally keep only four categories of binary mixtures based on their association behavior. These four categories correspond to the four bullet points mentioned previously, and the reader can also refer to Table 1 . The final mark that characterizes the model is the average of the four marks attained previously.

For further details on the exact methodology used, the reader is referred to the original publication. ${ }^{8}$ Finally, the PengRobinson $^{9}$ (PR) EoS with classical van der Waals one fluid theory (vdW1f) mixing rules and a temperature-dependent binary interaction parameter ${ }^{10}$ (BIP) was graded. The BIP was regressed from the experimental data available in the proposed database. $^{8}$

In this work, the perturbed chain-statistical associating fluid theory (PC-SAFT) ${ }^{11,12}$ EoS is applied without the use of any BIPs, and the predictions of the model are compared against the experimental data of the benchmark database of Jaubert et al. ${ }^{8}$ The EoS is graded using the proposed methodology, and the resulting marks, as well as the behavior of the model, for the various groups of mixtures are discussed and analyzed. Comparison against the previously assessed ${ }^{8} \mathrm{PR}$ EoS using the same database is provided.

\section{GRADING OF THE PC-SAFT EOS}

2.1. EoS Implementation. Statistical associating fluid theory (SAFT)-based EoSs are models that are theoretically derived by applying rigorous perturbation theory, ${ }^{13-15}$ while their basis lies in the first-order thermodynamic perturbation theory (TPT1). TPT1 was developed by Wertheim, ${ }^{16-19}$ who proposed a model for systems with highly directional forces, with a repulsive core and multiple attractive sites. The model of Wertheim allows the formation of chains and closed rings, as well as hydrogen bonding. Wertheim expanded the Helmholtz free energy in a series of integrals of molecular distribution functions and the association potential and derived a simplified expression. In this way, the Helmholtz free energy of a fluid can be described as the sum of the Helmholtz free energy of a simple reference fluid, which is known accurately, and a perturbation term, the development of which is challenging.

A variety of SAFT-based EoSs have been proposed in the literature, which differ mainly in the intermolecular potential 
used to model the reference fluid. The hard sphere system was the one used mainly as the reference fluid in the early proposed SAFT EoS. Based on this reference fluid, the perturbation terms were developed to account for dispersion forces, formation of chains, and intermolecular association phenomena. Later on, reference fluids that are allowed to interact with different potentials (square-well, Lennard-Jones, etc.) were employed, resulting also in different chain and association terms. In this common framework, SAFT-type EoSs are written as summations of Helmholtz free energy terms corresponding to different types of molecular interactions.

A SAFT model that has gained significant industrial popularity and has been incorporated in most commercially available process simulators is the PC-SAFT EoS. ${ }^{11}$ To derive PC-SAFT, the hard chain fluid was used as the reference system by Gross and Sadowski, who also applied second-order BarkerHenderson perturbation theory to develop the Helmholtz free energy term that accounts for the dispersion interactions. The pair potential used is the modified square well potential, proposed by Chen and Kreglewski. ${ }^{20}$ The chain and association terms in PC-SAFT EoS are the same as the ones used in the SAFT EoS proposed by Huang and Radosz. ${ }^{21,22}$ These chain and association terms were developed by applying TPT 1 on the hard sphere reference fluid. PC-SAFT is commonly written as a summation of the Helmholtz free energy terms, and the reader can refer to the original publications ${ }^{11,12}$ for the exact mathematical relations:

$$
\frac{\tilde{a}^{\mathrm{RES}}}{R T}=\frac{\tilde{a}^{\mathrm{HC}}}{R T}+\frac{\tilde{a}^{\mathrm{DISP}}}{R T}+\frac{\tilde{a}^{\mathrm{ASSOC}}}{R T}
$$

where $\tilde{a}$ is the molar Helmholtz free energy and the superscripts refer to the respective molecular interaction contributions. The expressions for the individual Helmholtz free energy terms used by the PC-SAFT EoS for mixtures are presented in the following equations:

$$
\begin{aligned}
\frac{\tilde{a}^{\mathrm{HS}}}{R T}= & \frac{1}{\zeta_{0}}\left[\frac{3 \zeta_{1} \zeta_{2}}{1-\zeta_{3}}+\frac{\zeta_{2}^{3}}{\zeta_{3}\left(1-\zeta_{3}\right)^{2}}+\left(\frac{\zeta_{2}^{3}}{\zeta_{3}^{2}}-\zeta_{0}\right)\right. \\
& \left.\ln \left(1-\zeta_{3}\right)\right] \\
\frac{\tilde{a}^{\mathrm{HC}}}{R T}= & \bar{m} \frac{\tilde{a}^{\mathrm{HS}}}{R T}-\sum_{i} x_{i}\left(m_{i}-1\right) \ln g_{i i}^{H S}\left(\sigma_{i i}\right) \\
\frac{\tilde{a}^{\mathrm{DISP}}}{R T}= & -2 \pi \hat{\rho} I_{1}(\eta, \bar{m}) \overline{m^{2} \varepsilon \sigma^{3}}-\pi \hat{\rho} \bar{m} C_{1} I_{2}(\eta, \bar{m}) \\
& \frac{m^{2} \varepsilon^{2} \sigma^{3}}{\frac{\tilde{a}^{\mathrm{ASSOC}}}{R T}}=\sum_{i} x_{i}\left[\sum_{A_{i}}\left(\ln X^{A_{i}}-\frac{X^{A_{i}}}{2}\right)+\frac{1}{2} M_{i}\right]
\end{aligned}
$$

where $x_{i}$ is the molar fraction of component $i$ in the mixture, $m_{i}$ is the number of spherical segments in a chain of component $i, \bar{m}$ is the mean segment number, $\sigma_{i}$ is the segment diameter of component $i, d_{i}$ is the temperature-dependent segment diameter of component $i, \varepsilon_{i}$ is the dispersion energy, and $g_{i i}^{\mathrm{HS}}\left(d_{i i}\right)$ is the radial pair distribution function of hard spheres of component $i$ at contact, given by the expression:

$$
\begin{gathered}
g_{i j}^{\mathrm{HS}}\left(d_{i j}\right)=\frac{1}{1-\zeta_{3}}+\left(\frac{d_{i} d_{j}}{d_{i}+d_{j}}\right) \frac{3 \zeta_{2}}{\left(1-\zeta_{3}\right)^{2}} \\
+\left(\frac{d_{i} d_{j}}{d_{i}+d_{j}}\right)^{2} \frac{2 \zeta_{2}^{2}}{\left(1-\zeta_{3}\right)^{2}} \\
\zeta_{n}=\frac{\pi}{6} \hat{\rho} \sum_{i} x_{i} m_{i} d_{i}^{n} \\
d_{i}=\sigma_{i}\left[1-0.12 \times \exp \left(-\frac{3 \varepsilon_{i}}{k_{B} T}\right)\right] \\
X^{A_{i}}=\left[1+\sum_{j} \sum_{B_{j}}^{M_{j}} \rho_{j} X^{B_{j}} \Delta^{A_{i} B_{j}}\right]^{-1} \\
\Delta^{A_{i} B_{j}}=d_{i j}^{3} g_{i j}^{\text {hs }}\left(d_{i j}\right) \kappa^{A_{\mathrm{i}} B_{j}}\left[\exp \left(\frac{\varepsilon^{A_{i} B_{j}}}{k_{B} T}\right)-1\right]
\end{gathered}
$$

where $\hat{\rho}$ is the number density of molecules and $I_{1}(\eta, \bar{m})$ and $I_{2}(\eta, \bar{m})$ are integrals calculated by power series in reduced density $\eta=\zeta_{3}$. $X^{A_{i}}$ is the fraction of molecules of species $i$ not bonded at site $A, M_{i}$ is the number of association sites on molecule $i$, and $\Delta^{A_{i} B_{j}}$ is the association strength between position $A$ of a molecule $i$ and position $B$ of a molecule $j . \varepsilon^{A_{i} B_{j}}$ is the association energy, and $\kappa^{A_{i} B_{j}}$ is the association volume.

One of the especially attractive features of the SAFT-type EoS, which stems from its theoretical origin, is that no mixing rules are needed in the chain and association terms. These terms are thus rigorously extended to mixtures. The extension of the EoS to mixtures requires however mixing rules for the dispersion term, and the vdW1f mixing rules are usually employed (also in this work), as proposed by Gross and Sadowski. ${ }^{11}$ Specific combining rules (Lorentz-Berthelot) are applied to calculate the segment dispersion energy and diameter parameters. Moreover, combining rules are needed for the association parameters in a mixture of $C$ components according to the expressions:

$$
\begin{aligned}
& \overline{m^{2} \frac{\varepsilon}{k_{B} T} \sigma^{3}}=\sum_{i=1}^{C} \sum_{j=1}^{C} x_{i} x_{j} m_{i} m_{j}\left[\frac{\varepsilon_{i j}}{k_{B} T}\right] \sigma_{i j}^{3} \\
& \overline{m^{2}\left[\frac{\varepsilon}{k_{B} T}\right]^{2}} \sigma^{3}=\sum_{i=1}^{C} \sum_{j=1}^{C} x_{i} x_{j} m_{i} m_{j}\left[\frac{\varepsilon_{i j}}{k_{B} T}\right]^{2} \sigma_{i j}^{3} \\
& \bar{m}=\sum_{i} x_{i} m_{i} \\
& \varepsilon_{i j}=\sqrt{\varepsilon_{i i} \varepsilon_{j j}}\left(1-k_{i j}\right) \\
& \sigma_{i j}=\frac{\sigma_{i i}+\sigma_{j j}}{2} \\
& \varepsilon^{A_{i} B_{j}}=\frac{1}{2}\left(\varepsilon^{A_{i} B_{i}}+\varepsilon^{A_{j} B_{j}}\right) \\
& \kappa^{A_{i} B_{j}}=\sqrt{\kappa^{A_{i} B_{i}} \kappa^{A_{j} B_{j}}}\left(\frac{\sqrt{\sigma_{i i} \sigma_{j j}}}{\frac{1}{2}\left(\sigma_{i i}+\sigma_{j j}\right)}\right)^{3}
\end{aligned}
$$


Table 2. Number of "Out of Model” Data Points, i.e., Points For Which the MAPE Cannot Be Evaluated ${ }^{a, b}$

\begin{tabular}{|c|c|c|c|c|c|}
\hline \multirow[b]{2}{*}{$\mathrm{BAC}$} & \multicolumn{5}{|c|}{ number of "out of model" data points/total number of data points } \\
\hline & liquid-phase composition & vapor phase (or second liquid phase) composition & three-phase line & critical point & azeotropic point \\
\hline 1 (NA-NA) & $515 / 3616(14.2 \%)$ & $507 / 3539(14.3 \%)$ & $12 / 16(75 \%)$ & $19 / 252(7.5 \%)$ & $8 / 11(72.7 \%)$ \\
\hline 2 (HA-NA) & $526 / 2601(20.2 \%)$ & $523 / 2554(20.5 \%)$ & & $141 / 319(44.2 \%)$ & $22 / 22(100 \%)$ \\
\hline 3 (HD-NA) & $442 / 1393(31.7 \%)$ & $442 / 1393(31.7 \%)$ & & $25 / 49(51 \%)$ & $43 / 44(97.7 \%)$ \\
\hline 4 (HA-HA or HD-HD) & $172 / 1465(11.7 \%)$ & $172 / 1465(10.8 \%)$ & & $7 / 60(11.6 \%)$ & $7 / 7(100 \%)$ \\
\hline 5 (SA-NA) & $714 / 1580(45.2 \%)$ & $713 / 1597(44.6 \%)$ & $16 / 25(64 \%)$ & $87 / 130(66.9 \%)$ & $5 / 35(14.3 \%)$ \\
\hline 6 (HD-HA) & $433 / 1522(28.4 \%)$ & $433 / 1522(28.4 \%)$ & & $23 / 63(36.5 \%)$ & $16 / 18(88.8 \%)$ \\
\hline 7 (SA-HD) & $121 / 741(16.3 \%)$ & $100 / 711(14.1 \%)$ & & & $1 / 13(7.7 \%)$ \\
\hline 8 (SA-HA) & $135 / 3055(4.4 \%)$ & $135 / 3000(4.5 \%)$ & $3 / 12(25 \%)$ & $60 / 193(31.1 \%)$ & $1 / 42(2.4 \%)$ \\
\hline 9 (SA-SA) & $338 / 2448(13.8 \%)$ & $320 / 2436(13.1 \%)$ & $13 / 13(100 \%)$ & $31 / 50(62 \%)$ & $10 / 33(30.3 \%)$ \\
\hline total & $3396 / 18,421(18.4 \%)$ & $3345 / 18,217(18.4 \%)$ & $44 / 66(66.6 \%)$ & $393 / 1116(35.2 \%)$ & $113 / 225(50.2 \%)$ \\
\hline
\end{tabular}

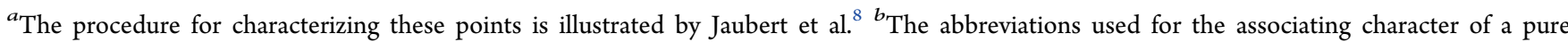
compound are: NA for "Non-Associating," HA for "Hydrogen-Acceptor", HD for "Hydrogen-Donor", and SA for "Self-Associating." Blanks indicate that no experimental data are available in the database for the respective properties. "Out of model" data points do not occur for enthalpy and heat capacity of mixing data, because it is always possible to calculate these properties at specified T, $\mathrm{P}$, and $\mathrm{z}_{1}$.

As it has already been mentioned in the introduction, a $k_{i j}$ equal to zero was used in the combining rules in this work, to grade the pure predictive capabilities of the EoS for mixtures.

PC-SAFT requires three pure component parameters $\left(m_{i}, \varepsilon_{i i}\right.$ and $\sigma_{i i}$ ) for non-self-associating compounds and five parameters $\left(m_{i}, \varepsilon_{i j}, \sigma_{i j}, \varepsilon^{A_{i} B_{i}}\right.$, and $\left.\kappa^{A_{i} B_{i}}\right)$ for self-associating ones, which are typically fitted to vapor pressure and saturated liquid density experimental data. For several components, the pure component parameters proposed by Moine et al. ${ }^{23}$ which are fitted to vapor pressure, saturated liquid density, enthalpy of vaporization, and saturated liquid heat capacity data were used. The pure component parameters used in this work are summarized in Table S1 in the Supporting Information. It has to be noted that no induced association scheme was employed for mixtures of a self-associating compound and a non-self-associating compound. Introducing induced association and evaluation of the effect on the accuracy of the PC-SAFT EoS will be the subject of a future publication.

Calculations with the PC-SAFT EoS were performed with the Physical Property Library (PPL), which is a collection of libraries written and compiled in FORTRAN 90/95. The source code was developed in the Molecular Thermodynamics and Modeling of Materials Laboratory (MTMML) in the National Center for Scientific Research "Demokritos" in Athens, Greece. The method of Topliss et al. ${ }^{24}$ was used to calculate the density with the PC-SAFT EoS. The calculation of the properties, based on which the grading of the EoS is carried out, is performed by specifying the free variables as proposed by Jaubert et al. ${ }^{8}$ These specifications are summarized in Table S2 in the Supporting Information.

For the calculation of the VLE or LLE, a stability test ${ }^{25}$ is performed initially and if the result corresponds to a non-stable mixture, then a PT-flash ${ }^{26}$ calculation is performed. In this way, the compositions of the two coexisting phases are determined. The composition space $\left(0 \leq z_{1} \leq 1\right.$ and $\left.z_{2}=1-z_{1}\right)$ is scanned until the feed phase composition is found to be non-stable. If no instability is found at a specified temperature and pressure, then the experimental data point is characterized as "out of model," because the model cannot reproduce the experimental twophase behavior. A detailed discussion about the characterization of "out of model" data points can be found in the study by Jaubert et al. ${ }^{8}$ The same procedure, without the scanning of the composition space (calculation is performed at specified temperature, pressure, and composition, as shown in Table
S2), is followed for the enthalpy and heat capacity of mixing calculation. If the mixture is stable, then the most stable state (liquid or vapor) for the mixture and the pure components has to be found. This is done by comparing the residual Gibbs free energies using the liquid and vapor density solutions of the EoS. Then, the enthalpy and heat capacity of mixing are calculated. If the mixture is found to be non-stable, then the procedure mentioned above is followed for each of the coexisting phases, and the final enthalpy or heat capacity of mixing is calculated as a weighted average (phase mole fraction is the weighting factor) of the enthalpies or heat capacities of mixing of the respective phases. A discussion around the mixing properties and how the aggregation states of the pure components and the mixture affect their calculation can be found in the study by Privat and Jaubert. $^{27,28}$

The calculation of the critical and azeotropic points is performed by sequentially tracing the phase diagrams of the binary mixtures at specified temperatures. The calculation is terminated when the compositions of the coexisting phases are sufficiently close (usually to the third decimal point for the molar fractions). The calculation of the VLLE is performed in a similar way. The binary phase diagram is sequentially traced, and if instability is found, a direct calculation of three-phase equilibrium is performed, as described in Chapter 12 of Michelsen and Mollerup. ${ }^{29}$

\section{RESULTS AND DISCUSSION}

3.1. Grading of the Results. For each BAC, the MAPEs on liquid-phase composition $x$, gas phase composition (or second liquid-phase composition) $y$, three-phase pressure $P_{L L V}$, threephase composition $z_{\mathrm{LLV}}$, critical pressure $P_{\mathcal{c}}$, critical composition $x_{\mathcal{c}}$, azeotropic pressure $P_{\text {azeo }}$ azeotropic composition $x_{\text {azeo }}$, mixing enthalpy $h^{M}$, and mixing heat capacity $c_{p}{ }^{M}$ are presented in Table 1 .

Following the procedure described by Jaubert et al., ${ }^{8}$ a number of experimental data points are characterized as "out of model" when the MAPE at these points cannot be calculated based on the criteria set by the methodology. "Out of model" points correspond to cases in which the model cannot reproduce qualitatively the experimental data behavior (for example, prediction of an inhomogeneous azeotrope instead of a homogeneous one, etc.), or very large deviations between model calculations and experiments, especially at compositions very close to 0 or 1 , are observed. Consequently, the number of 
Table 3. Rating of the Nine BACs To Finally Grade the Model (PC-SAFT EoS with vdW1f Mixing Rules and no BIPs) ${ }^{a}$

\begin{tabular}{|c|c|c|c|c|c|c|c|c|c|c|c|c|c|}
\hline \multirow[b]{2}{*}{ BAC } & \multicolumn{10}{|c|}{ mark on: } & \multirow[b]{2}{*}{$\begin{array}{l}\text { BAC } \\
\text { mark }\end{array}$} & \multirow[b]{2}{*}{$\begin{array}{c}\text { mark (over } 20 \text { ) by type of } \\
\text { association }\end{array}$} & \multirow[b]{2}{*}{$\begin{array}{l}\text { final } \\
\text { mark }\end{array}$} \\
\hline & $x$ & $y$ & $P_{\mathrm{LLV}}$ & $z_{\mathrm{LLV}}$ & $P_{c}$ & $x_{c}$ & $P_{\text {azeo }}$ & $x_{\text {azeo }}$ & $h^{M}$ & $c_{p}{ }^{M}$ & & & \\
\hline 1 (NA-NA) & 12.7 & 14.4 & 17.9 & 0.0 & 15.1 & 2.0 & 17.4 & 0.0 & 4.3 & 1.0 & 8.5 & \multirow{4}{*}{$\operatorname{Mark}_{\mathrm{NA}}=5.5$} & \multirow{9}{*}{$5.1 / 20$} \\
\hline 2 (HA-NA) & 0.0 & 6.5 & & & 7.8 & 0.0 & - & - & 2.2 & 6.5 & 3.8 & & \\
\hline 3 (HD-NA) & 0.0 & 2.5 & & & 12.0 & 2.0 & 12.4 & 0.3 & 0.4 & 1.6 & 3.9 & & \\
\hline 4 (HA-HA or HD-HD) & 3.6 & 8.0 & & & 5.7 & 0.0 & - & - & 7.5 & 10.4 & 5.9 & & \\
\hline 5 (SA-NA) & 0.0 & 9.1 & 18.5 & 0.0 & 0.0 & 0.0 & 15.5 & 10.6 & 8.6 & 14.4 & 7.7 & $\operatorname{Mark}_{\mathrm{SA}}=7.7$ & \\
\hline 6 (HD-HA) & 0.0 & 0.0 & & & 7.1 & 0.0 & 7.1 & 0.0 & 0.0 & 0.0 & 1.8 & Mark $_{\mathrm{CA}}=1.8$ & \\
\hline 7 (SA-HD) & 1.5 & 10.1 & & & & & 16.9 & 9.6 & 4.2 & 2.9 & 7.5 & \multirow{3}{*}{$\operatorname{Mark}_{\mathrm{CA}+\mathrm{SA}}=5.5$} & \\
\hline 8 (SA-HA) & 0.0 & 4.2 & 10.4 & 0.0 & 0.0 & 0.0 & 9.7 & 0.0 & 6.6 & 11.9 & 4.3 & & \\
\hline 9 (SA-SA) & 0.0 & 4.8 & - & - & 0.0 & 0.0 & 18.3 & 5.1 & 3.2 & 7.1 & 4.8 & & \\
\hline
\end{tabular}

${ }^{a}$ The abbreviations used for the associating character of a pure compound are: NA for "Non-Associating," HA for "Hydrogen-Acceptor", HD for "Hydrogen-Donor", and SA for "Self-Associating." Blanks indicate that no experimental data are available in the database for the respective properties, while dashes indicate that all calculations are deemed "out of model."
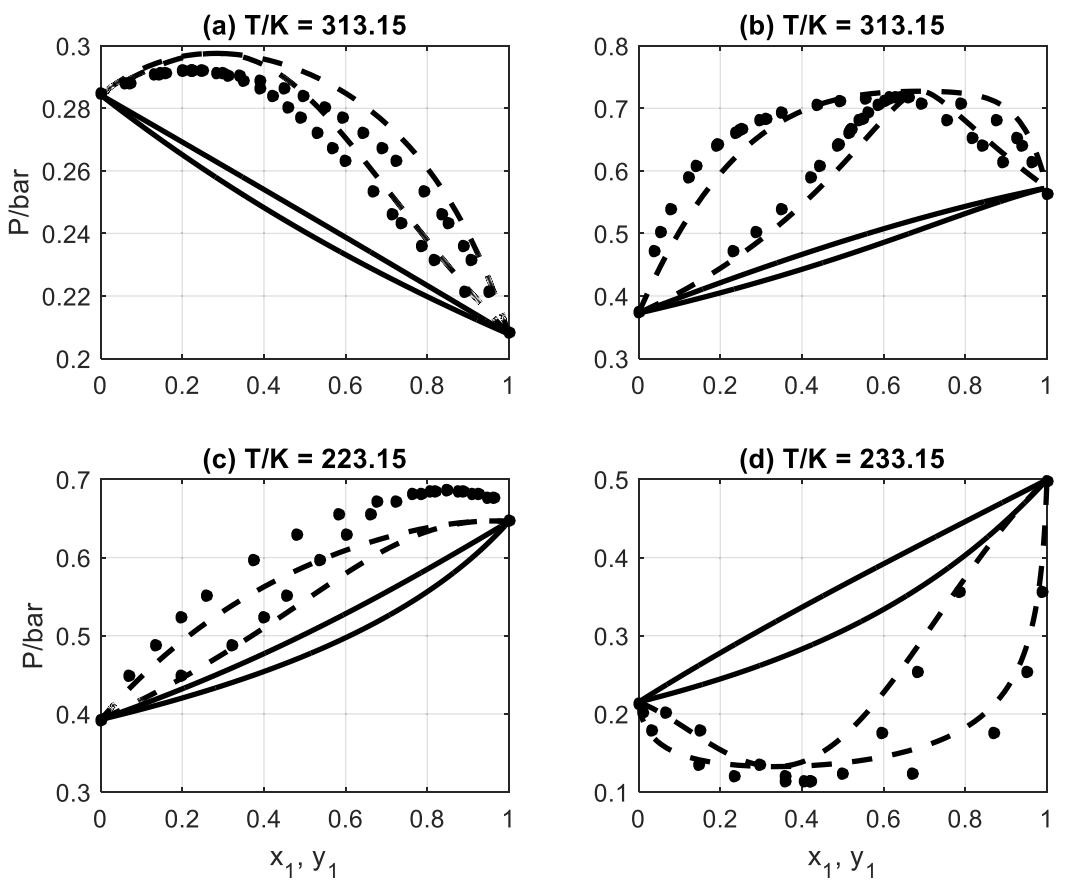

Figure 1. Pressure-composition VLE phase diagrams for the (a) 1,2-dichloroethane (1)-carbon tetrachloride $\left(\mathrm{BAC}_{1}\right),(\mathrm{b})$ acetone $(1)-n$-hexane $\left(\mathrm{BAC}_{2}\right),(\mathrm{c})$ chlorodifluoromethane (1)-dichlorodifluoromethane $\left(\mathrm{BAC}_{3}\right)$, and (d) dimethyl ether (1)-sulfur dioxide $\left(\mathrm{BAC}_{4}\right)$ mixtures. Experimental data are represented by points, predictions from the PC-SAFT EoS with vdW1f mixing rules and no BIPs by lines and calculations with the PC-SAFT EoS with vdW1f mixing rules and regressed BIPs by dashed lines. The regressed BIPs are: (a) $k_{i j}=0.0275$, (b) $k_{i j}=0.0625$, (c) $k_{i j}=$ 0.0275 and $(\mathrm{d}) k_{i j}=-0.13$.

"out of model" points gives a good insight into the performance of a model, additionally to the MAPEs. Table 2 summarizes the "out of model" data points for the PC-SAFT EoS, as implemented in this work, for the different BACs and different categories of available experimental data. Furthermore, in Table 2 the total sum of "out of model" data points for each experimental data category and the percentage of these points over the total available data for each property considered are presented.

The calculated MAPEs are utilized to give a mark (score over 20) to each of the nine BACs by averaging the 10 marks of the properties considered $\left(x, y, P_{\mathrm{LLV}}, z_{\mathrm{LLV}}, P_{c}, x_{c}, P_{\text {azeo }}, x_{\text {azeo }}, h^{M}\right.$, and $\left.c_{p}{ }^{M}\right)$. Table 3 summarizes these marks. As proposed by Jaubert et $\mathrm{al}^{8}$ the marks obtained by BACs 1 to 4 and BACs 7 to 9 are averaged to only retain four categories $\left(\mathrm{BAC}_{1}-\mathrm{BAC}_{4}, \mathrm{BAC}_{5}\right.$, $\mathrm{BAC}_{6}$, and $\mathrm{BAC}_{7}-\mathrm{BAC}_{9}$ ) of binary systems based on the type of association they exhibit. By averaging the marks of these four categories, the PC-SAFT EoS with vdW1f mixing rules and no BIP scores a final mark of 5.1/20.

3.2. Discussion. In this section, the results obtained with the implementation of the PC-SAFT EoS are discussed and analyzed. The most accurately predicted behavior is that of mixtures belonging to $\mathrm{BAC}_{1}$ with a mark of $8.5 / 20$. This category consists of mixtures where no association takes place and the individual components do not possess either a hydrogen donor or a hydrogen acceptor. In the non-associating category 
(a) $\mathrm{T} / \mathrm{K}=288.15 \mathrm{P} / \mathrm{bar}=1.0132$

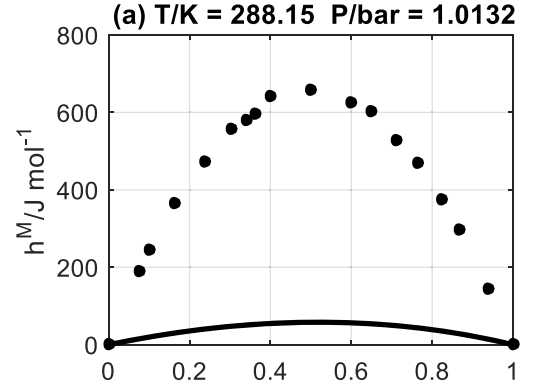

(c) $\mathrm{T} / \mathrm{K}=298.15 \mathrm{P} / \mathrm{bar}=1.01$

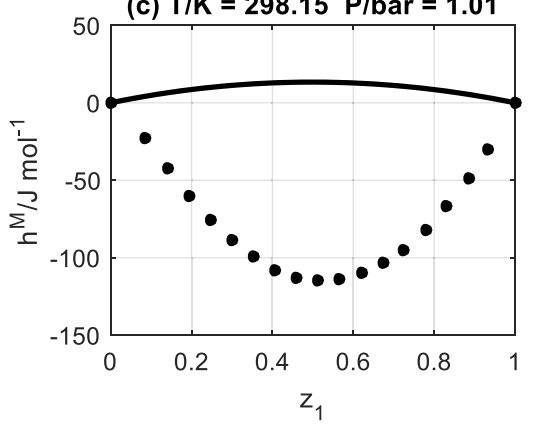

(b) $\mathrm{T} / \mathrm{K}=243.2 \mathrm{P} / \mathrm{bar}=1.0132$

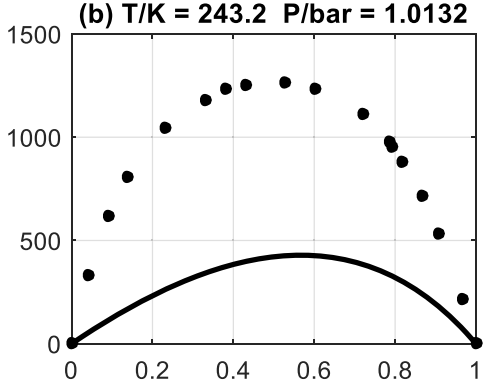

(d) $\mathrm{T} / \mathrm{K}=298.15 \mathrm{P} / \mathrm{bar}=60$

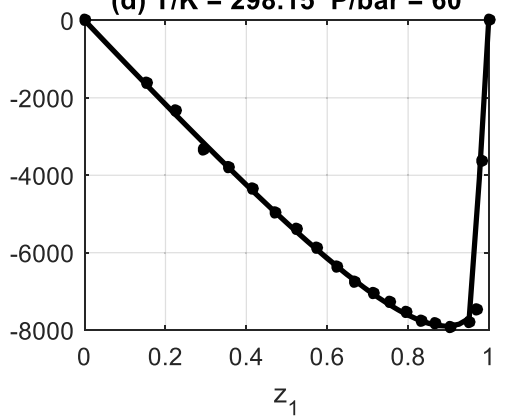

Figure 2. Enthalpy of mixing-composition diagrams for (a) 1,2-dichloroethane (1)-carbon tetrachloride $\left(\mathrm{BAC}_{1}\right),(\mathrm{b})$ acetone (1)- $n$-hexane $\left(\mathrm{BAC}_{2}\right),(\mathrm{c})$ chloroform $(1)-1,2$-dichloroethane $\left(\mathrm{BAC}_{3}\right)$, and $(\mathrm{d})$ carbon dioxide $(1)$-dimethyl carbonate $\left(\mathrm{BAC}_{4}\right)$ mixtures. Experimental data are represented by points and predictions from the PC-SAFT EoS with vdW1f mixing rules and no BIPs by lines.

also fall the mixtures of $\mathrm{BAC}_{2}, \mathrm{BAC}_{3}$, and $\mathrm{BAC}_{4}$. However, the marks achieved in these cases are significantly lower than the $\mathrm{BAC}_{1}$ mark with scores of $3.8,3.9$, and 5.9/20, respectively. The average mark achieved for the non-associating systems is mark $_{\mathrm{NA}}$ $=5.5$. Non-associating systems often belong to type-I systems in the classification scheme of Van Konynenburg and Scott, ${ }^{30,31}$ but some fall into type-III, especially when the two compounds show a high size-asymmetry.

It has to be noted at this point that the "out of model" data points for the non-associating systems $\left(\mathrm{BAC}_{1}-\mathrm{BAC}_{4}\right)$ are around $19 \%$ of the available liquid phase and vapor phase experimental data in the database for these mixtures. However, regarding the azeotropic point data, the "out of model" data points are $95 \%$ of the total experimental points available for these mixtures. This shows clearly that the very low marks scored are mainly due to the inaccurate prediction of the mixtures that exhibit azeotropy. More specifically, the EoS does not reproduce even qualitatively the behavior of any mixture included in $\mathrm{BAC}_{1}-\mathrm{BAC}_{4}$ that exhibits azeotropy. This result corroborates what was observed by Jaubert and Privat ${ }^{32}$ when they tried to model the carbon dioxide-ethane binary system with the PCSAFT EoS and a $k_{i j}$ equal to zero. Twenty mixtures in total exhibit azeotropic behavior in the non-associating group of mixtures of the 92 available.

More generally, Jaubert and Privat ${ }^{32}$ showed that the PCSAFT EoS with no $k_{i j}$ has a natural tendency to predict negative deviations from ideality (because, under infinite pressure, the excess Gibbs energy predicted by the EoS always tends to $-\infty$ ). However, it should be noted that by moving away from the infinite pressure domain, the PC-SAFT EoS may predict positive deviations from ideality with a $k_{i j}$ equal to zero. However, for the reason previously mentioned, it will more easily predict negative deviations. In practice, the fact that positive deviations are much more frequent than negative deviations in real systems could explain the low score associated with $\mathrm{BAC}_{1}-\mathrm{BAC}_{4}$.
In Figure 1, pressure-composition VLE phase diagrams for four mixtures of the BACs discussed previously, which exhibit azeotropic behavior, are presented. The results are characteristic of all the mixtures in this category that form an azeotrope. Clearly, the PC-SAFT EoS predicts very small deviations from ideality (positive or negative) for all mixtures. Considering, all mixtures in $\mathrm{BAC}_{1}-\mathrm{BAC}_{4}$, only the dimethyl ether-sulfur dioxide mixture forms a negative azeotrope, and the PC-SAFT EoS predicts nearly ideal behavior. It is also worth noting that between the four BACs of the non-associating group, the PCSAFT EoS performs worse (based on the average BAC mark) for $\mathrm{BAC}_{2}$ and $\mathrm{BAC}_{3}$ in which a molecule with a hydrogen donor or acceptor is mixed with a non-associating molecule. In Figure 2, enthalpy of mixing-composition diagrams for four mixtures that belong to $\mathrm{BAC}_{1}, \mathrm{BAC}_{2}, \mathrm{BAC}_{3}$, and $\mathrm{BAC}_{4}$ groups are presented. In three out of the four mixtures examined, the model is in poor agreement with experimental data.

The second highest score, when all BACs are considered, and the highest one after the averaging in four general groups are achieved for the $\mathrm{BAC}_{5}$ group with mark $\mathrm{SA}_{\mathrm{A}}=7.7$. In systems belonging to this group, a non-associating component is mixed with a self-associating one so that self-association (partially) appears in the mixture. Positive deviations from ideality, threephase equilibrium at low temperatures, and liquid-phase splitting are often observed in this family of mixtures. Many of them belong to type-III systems in the classification scheme of Van Konynenburg and Scott. ${ }^{30}$ All binary water-n-alkane or alcohol- $n$-alkane mixtures belong to this family, and it is generally accepted that it is the most difficult family of mixtures to describe with a thermodynamic model. ${ }^{8}$

Considering the performance of the PC-SAFT EoS for the previous BACs, it is both interesting but also expected that the model performs better for this group of mixtures that exhibit a more complex behavior. This can be predominantly attributed to the association term of PC-SAFT, because in the previous cases no self-associating compounds were considered. As it has 

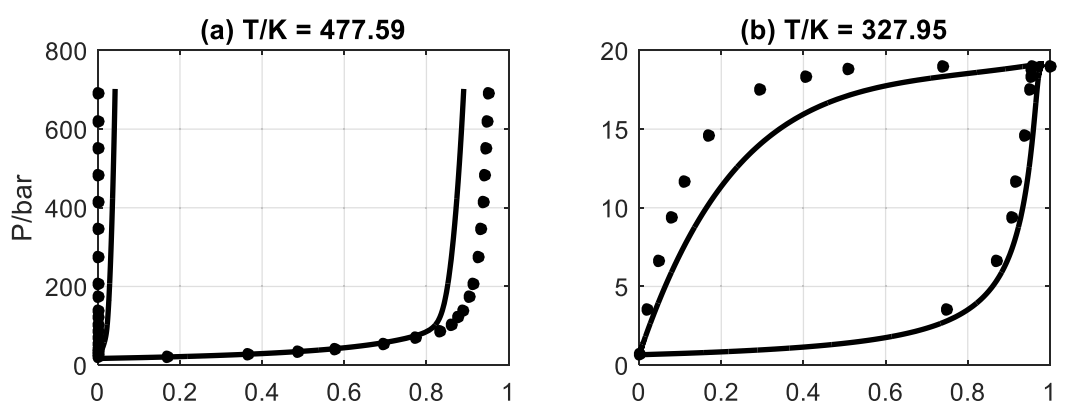

(c) $\mathrm{T} / \mathrm{K}=318.15$
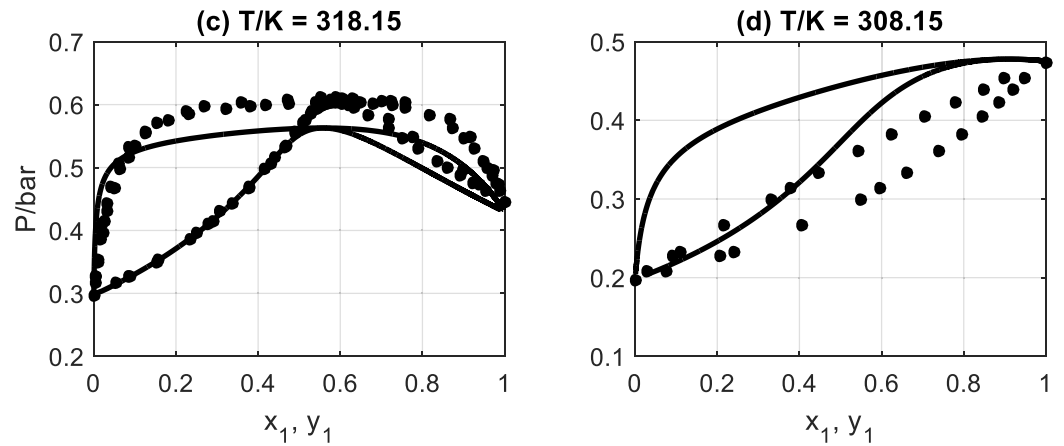

Figure 3. Pressure-composition VLE phase diagrams for (a) $n$-butane (1)-water $\left(\mathrm{BAC}_{5}\right)$, (b) propane (1)-methanol (BAC 5$)$, (c) methanol (1)benzene $\left(\mathrm{BAC}_{5}\right)$, and $(\mathrm{d})$ diethylamine $(1)$-benzene $\left(\mathrm{BAC}_{5}\right)$ mixtures. Experimental data are represented by points and predictions from the PCSAFT EoS with vdW1f mixing rules and no BIPs by lines.
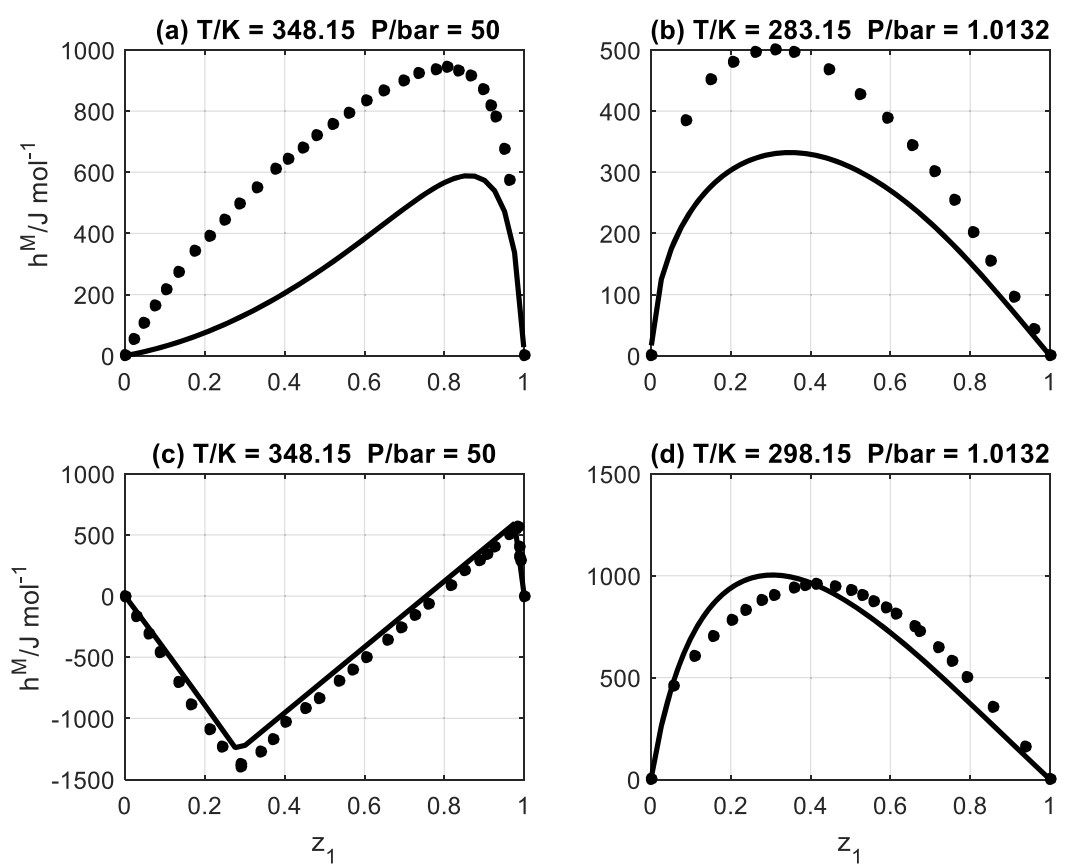

Figure 4. Enthalpy of mixing-composition diagrams for (a) propane (1)-methanol $\left(\mathrm{BAC}_{5}\right),(\mathrm{b})$ methanol (1)-benzene $\left(\mathrm{BAC}_{5}\right)$, (c) ethane $(1)-1$ propanol $\left(\mathrm{BAC}_{5}\right)$, and $(\mathrm{d})$ 2-butanol (1)-cyclohexane $\left(\mathrm{BAC}_{5}\right)$ mixtures. Experimental data are represented by points and predictions from the PCSAFT EoS with vdW1f mixing rules and no BIPs by lines.

already been mentioned, in this particular family self-association (partially) persists in the mixture, and the association term of PC-SAFT accounts for the hydrogen bonding interactions between like molecules. Jaubert et al. ${ }^{8}$ have shown that the PR EoS with vdW1f mixing rules and a temperature-dependent $k_{i j}$ correlates with high-accuracy $\mathrm{BAC}_{1}-\mathrm{BAC}_{4}$ and $\mathrm{BAC}_{6}$, with a lower accuracy $\mathrm{BAC}_{7}-\mathrm{BAC}_{9}$ and with the lowest score (8.4) $\mathrm{BAC}_{5}$. Of course, this mark is higher than the respective one of the PC-SAFT EoS as implemented in this work but significantly lower than the excellent ones achieved for the other BACs. Jaubert et al. ${ }^{8}$ also stated that the addition of an association term or the use of more sophisticated mixing rules could help the PR $\mathrm{EoS}$ to quantitatively reproduce the behavior of such systems $\left(\mathrm{BAC}_{5}\right)$.

In Figure 3, pressure-composition VLE phase diagrams for four mixtures of $\mathrm{BAC}_{5}$ are presented, including azeotropic behavior and open and close ended phase diagrams. In contrast to the previous BACs, there are only $14 \%$ "out of model" 
(a) $T / K=318.15$

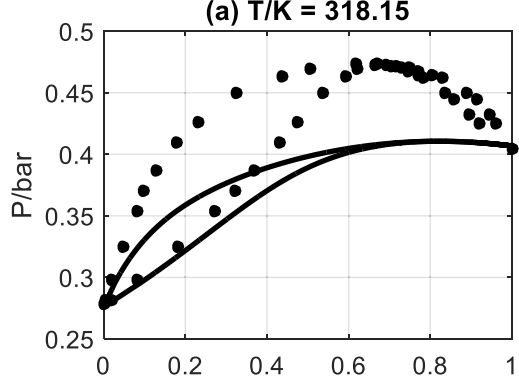

(c) $\mathrm{T} / \mathrm{K}=328.15$

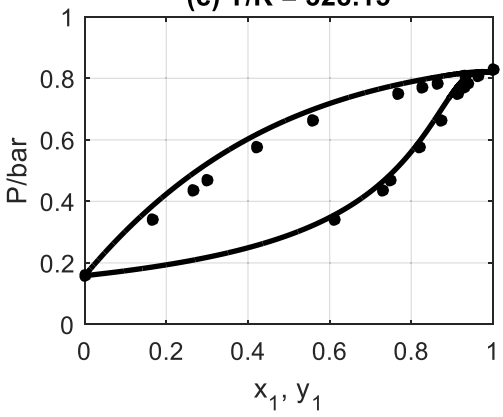

(b) $\mathrm{T} / \mathrm{K}=\mathbf{3 2 8 . 1 5}$

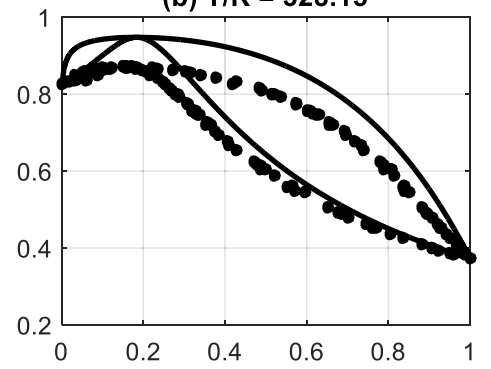

(d) $T / K=341.01$

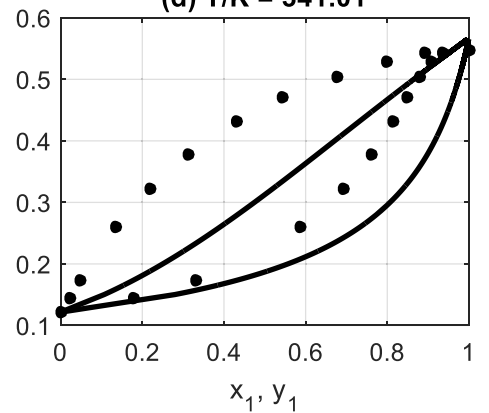

Figure 5. Pressure-composition VLE phase diagrams for (a) 1-hexyne (1)-acetonitrile $\left(\mathrm{BAC}_{7}\right)$, (b) ethanol (1)-chloroform $\left(\mathrm{BAC}_{7}\right)$, (c) chloroform (1)-1-propanol $\left(\mathrm{BAC}_{7}\right)$, and $(\mathrm{d})$ trichloroethylene (1)-2-methoxyethanol $\left(\mathrm{BAC}_{7}\right)$ mixtures. Experimental data are represented by points and predictions from the PC-SAFT EoS with vdW1f mixing rules and no BIPs by lines.

azeotropic data points of the total available, which means that the qualitative prediction of the behavior is more accurate for this family of mixtures. However, $45 \%$ of VLE (or LLE) predictions are characterized as "out of model," which is mainly attributed to the underprediction of the azeotropic pressure in all mixtures examined. A significant amount of "out of model" data points are observed for critical points (67\%) and threephase equilibrium (64\%) predictions. This is also reflected in the respective marks. It is also worth noting that the grades received for the enthalpy and heat capacity of mixing of $\mathrm{BAC}_{5}$ are the best in general among all BACs. Enthalpy of mixing results for the BAC5 group are presented in Figure 4. The agreement between experimental data and PC-SAFT prediction is fair.

The poorest rating among all BACs (before and after the averaging in four general categories) is the one achieved for $\mathrm{BAC}_{6}$ with mark $\mathrm{CA}_{\mathrm{A}}=1.8$. The binary systems that belong to this group exhibit cross-association, but the individual compounds do not self-associate. In this case, the association term of the PCSAFT EoS was not employed. For such binary systems, the two components form hydrogen bonds when mixing thus stabilizing the liquid phase and preventing phase splitting. As a general rule, mixtures of this family exhibit negative deviations from ideality and belong to type-I classification.

The qualitative results for $\mathrm{BAC}_{6}$ are very similar to those of $\mathrm{BAC}_{2}, \mathrm{BAC}_{3}$, and $\mathrm{BAC}_{4}$; that is, the PC-SAFT EoS predicts small deviations from ideality (positive or negative) for all mixtures in the group. All the mixtures included in $\mathrm{BAC}_{6}$ that exhibit azeotropic behavior form negative azeotropes, a behavior which the model does not reproduce, except for the 1,1,1,2,3,3,3-heptafluoropropane-sulfur dioxide mixture, which forms a positive azeotrope. In this particular case, the PC-SAFT EoS reproduces qualitatively correctly the azeotropic behavior. The enthalpy and heat capacity of mixing prediction for $\mathrm{BAC}_{6}$ are significantly worse both qualitatively and quantitatively as compared to $\mathrm{BAC}_{1}-\mathrm{BAC}_{4}$ results, as shown both by the difference in MAPEs and the zero marks received for these two properties.

Finally, mixtures in which both cross-association and selfassociation take place $\left(\mathrm{BAC}_{7}-\mathrm{BAC}_{9}\right)$ receive an average $\operatorname{mark}_{\mathrm{CA}+\mathrm{SA}}=5.5$. In these mixtures, hydrogen bonds between two identical self-associating molecules are broken by dilution effects, and new hydrogen bonds are formed by crossassociation. Many of these mixtures belong to type-I systems in the classification scheme of Van Konynenburg and Scott, ${ }^{30}$ and some fall into type-III.

As it has already been discussed in the previous paragraphs, mixtures in which self-association dominates are described with much higher accuracy by the PC-SAFT EoS than those that exhibit only cross-association. Therefore, it is expected that the final grades for $\mathrm{BAC}_{7}$ and $\mathrm{BAC}_{8}$ should be in between those achieved in $\mathrm{BAC}_{5}$ and $\mathrm{BAC}_{6}$. This is also verified by the results presented in Table 3. The average marks received for $\mathrm{BAC}_{7}$ and $\mathrm{BAC}_{8}$ are 7.5 and $4.3 / 20$, respectively, showing a relatively significant difference in the performance of the EoS for the two groups. However, no three-phase equilibrium and critical point data are available for $\mathrm{BAC}_{7}$, to deduce direct comparison between the two groups. Regarding the $\mathrm{BAC}_{8}$ group, it is interesting to note that the mark received by this family of mixtures is close to the marks received by $\mathrm{BAC}_{2}$ and $\mathrm{BAC}_{3}$ groups. By further analyzing the marks, it seems that this equivalence occurs by a counterbalance between the more accurate predictions of the azeotropic behavior, enthalpy, and heat capacity of mixing in $\mathrm{BAC}_{8}$ as opposed to the more accurate prediction of critical points in $\mathrm{BAC}_{2}$ and $\mathrm{BAC}_{3}$. However, the "out of model" critical points for $\mathrm{BAC}_{2}$ and $\mathrm{BAC}_{3}$ are 44 and $51 \%$, respectively, whereas the "out of model" critical points for $\mathrm{BAC}_{8}$ are $31 \%$.

$\mathrm{BAC}_{9}$ receives a mark of $4.8 / 20$ scoring in between (closer to the $\mathrm{BAC}_{8}$ group) $\mathrm{BAC}_{7}$ and $\mathrm{BAC}_{8}$ groups. The mixtures included in this group consist of two self-associating components, and consequently, combining rules in the 
(a) $T / K=308.15$

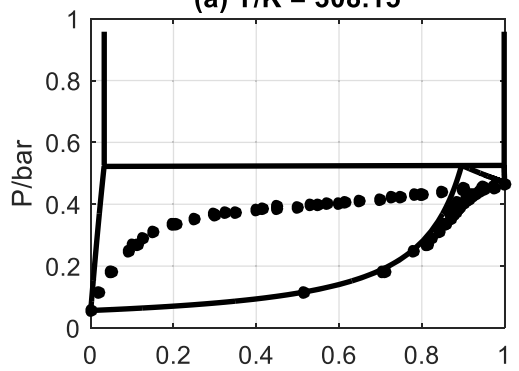

(c) $T / K=315.15$

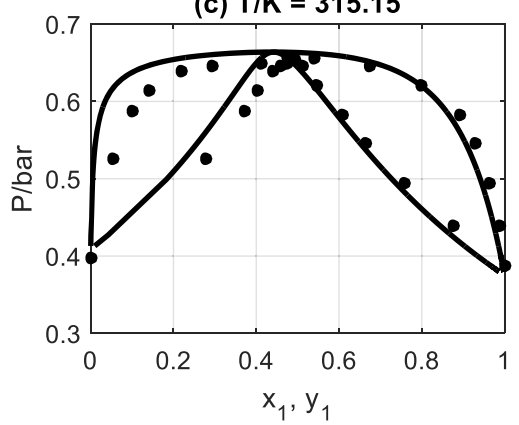

(b) $\mathrm{T} / \mathrm{K}=\mathbf{3 3 0}$

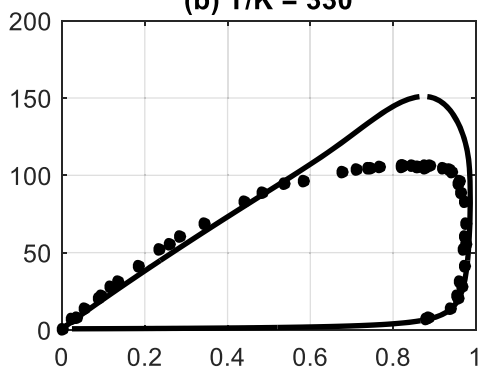

(d) $\mathrm{T} / \mathrm{K}=348.15$

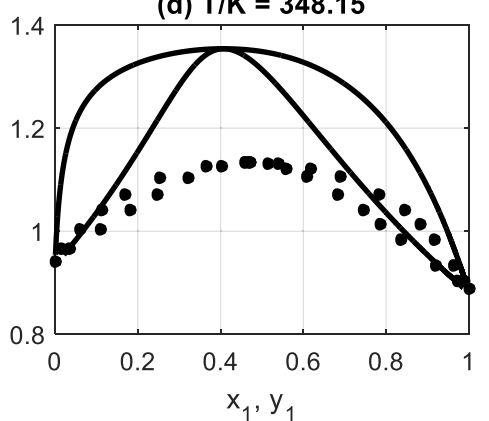

Figure 6. Pressure-composition VLE phase diagrams for (a) acetone (1)-water $\left(\mathrm{BAC}_{8}\right)$, (b) carbon dioxide (1)-methanol (BAC $)$, (c) methanol (1)-diisopropyl ether $\left(\mathrm{BAC}_{8}\right)$, and $(\mathrm{d})$ ethanol (1) - ethyl acetate $\left(\mathrm{BAC}_{8}\right)$ mixtures. Experimental data are represented by points and predictions from the PC-SAFT EoS with vdWif mixing rules and no BIPs by lines
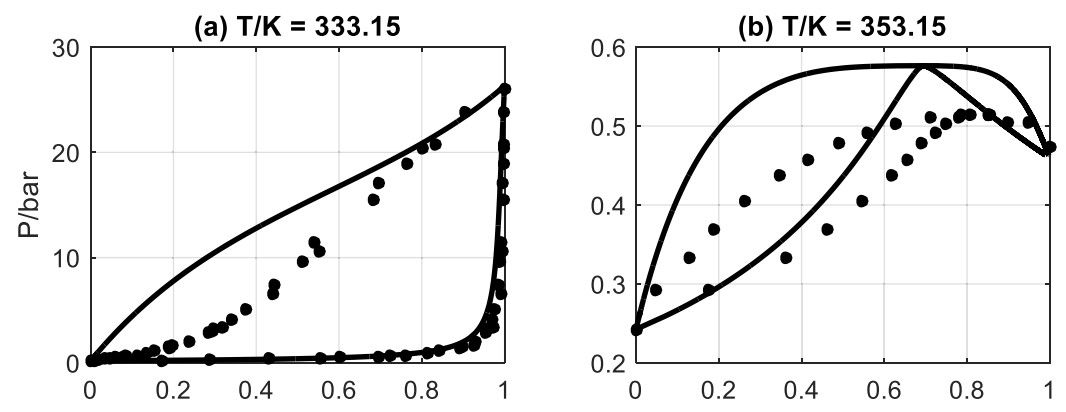

(c) $T / K=333.15$
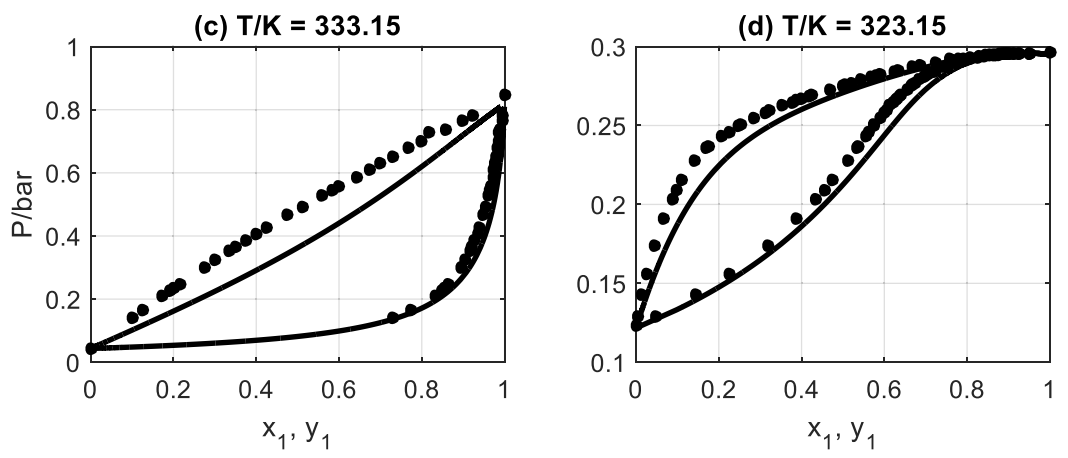

Figure 7. Pressure-composition VLE phase diagrams for (a) ammonia (1)-water (BAC 9 ), (b) water (1)-propylene glycol monomethyl ether $\left(\mathrm{BAC}_{9}\right),(\mathrm{c})$ methanol (1)-3-methyl-1-butanol $\left(\mathrm{BAC}_{9}\right)$, and $(\mathrm{d})$ ethanol $(1)$-water $\left(\mathrm{BAC}_{9}\right)$ mixtures. Experimental data are represented by points and predictions from the PC-SAFT EoS with vdW1f mixing rules and no BIPs by lines.

association term are also applied to calculate the crossassociation energy between unlike molecules. Inclusion of these combining rules introduces an extra simplification in the model that tries to capture complex interactions between like and unlike molecules that strongly associate.

In Figures 5-8, some characteristic results for mixtures belonging to $\mathrm{BAC}_{7}-\mathrm{BAC}_{9}$ are presented. Contrary to the previous BACs in which the predictions of PC-SAFT EoS were relatively uniform, that is, small positive or negative deviations from ideality with accurate or inaccurate results $\left(\mathrm{BAC}_{1}-\mathrm{BAC}_{4}\right.$ and $\mathrm{BAC}_{6}$ ), for mixtures belonging to $\mathrm{BAC}_{7}-\mathrm{BAC}_{9}$ this is not the case, with predictions spanning from very accurate ones for azeotropic mixtures such as methanol-diisopropyl ether $\left(\mathrm{BAC}_{8}\right)$ (Figure $6 \mathrm{c}$ ) to under or overprediction of the azeotropic pressure for other mixtures, such as 1-hexyne-acetonitrile $\left(\mathrm{BAC}_{7}\right)$ (Figure $\left.5 \mathrm{a}\right)$ and ethanol-chloroform $\left(\mathrm{BAC}_{7}\right)$ (Figure 

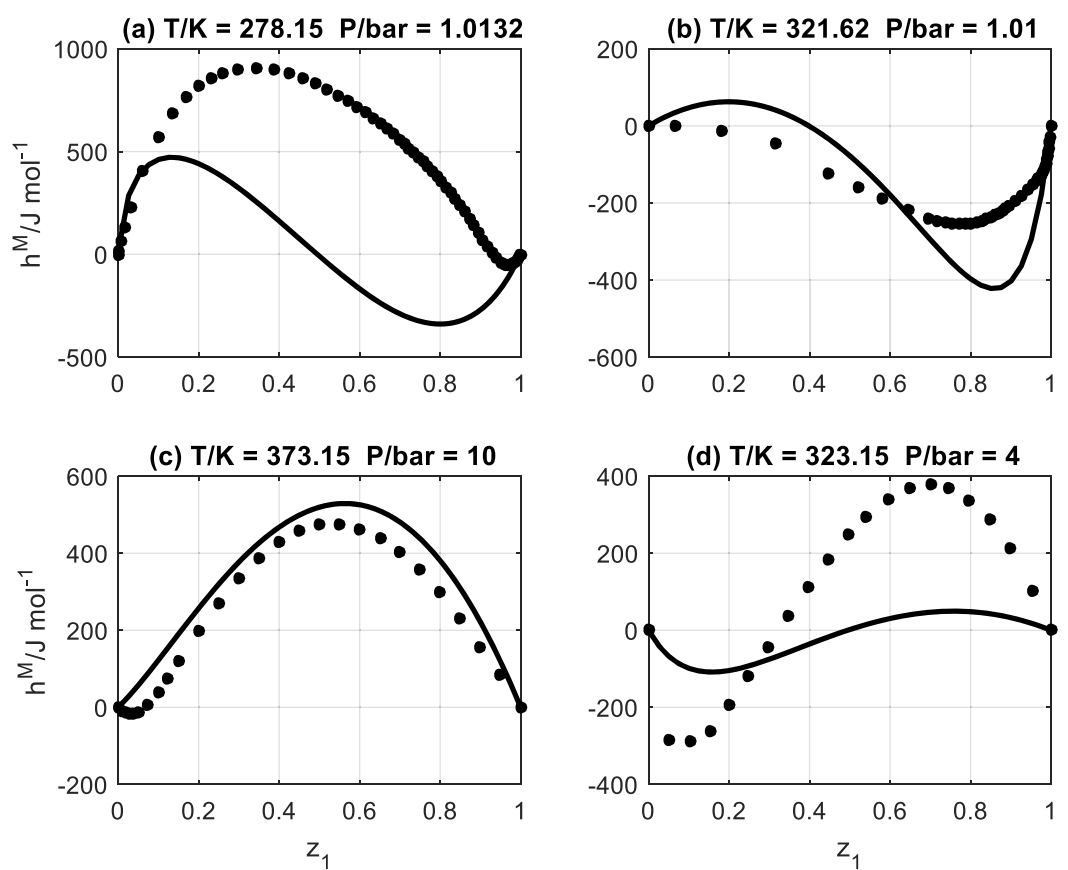

Figure 8. Enthalpy of mixing-composition diagrams for (a) water (1)-acetonitrile $\left(\mathrm{BAC}_{9}\right),(\mathrm{b})$ water (1)-2-butoxyethanol (BAC $)$, (c) ethanol $(1)$-water $\left(\mathrm{BAC}_{9}\right)$, and $(\mathrm{d})$ iso-propanol $(1)$ - water $\left(\mathrm{BAC}_{9}\right)$ mixtures. Experimental data are represented by points and predictions from the PCSAFT EoS with vdW1f mixing rules and no BIPs by lines.
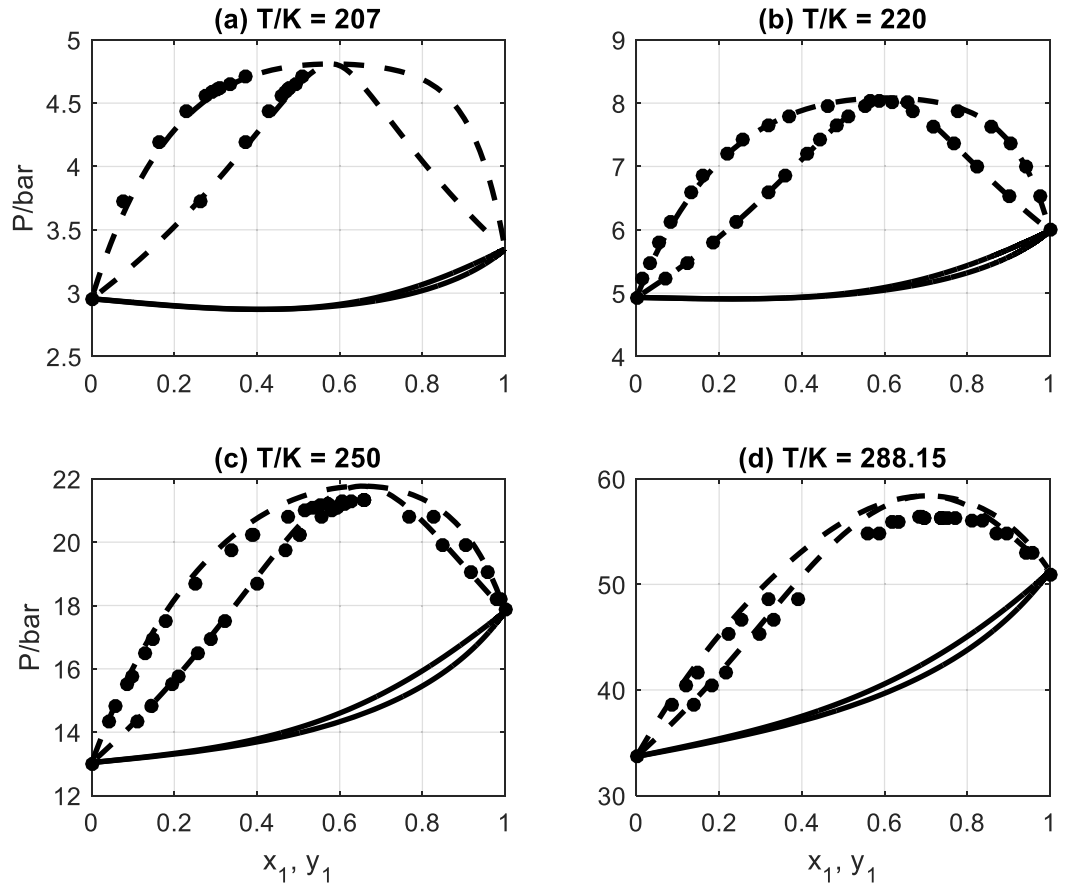

Figure 9. Pressure-composition VLE phase diagrams for the carbon dioxide (1)-ethane $\left(\mathrm{BAC}_{2}\right)$ mixture at various temperatures. Experimental data are represented by points, predictions of PC-SAFT EoS with vdW1f mixing rules and no BIPs by solid lines, and calculations with PC-SAFT EoS with vdW1f mixing rules and $k_{i j}=0.1125$ by dashed lines.

$5 b)$. Prediction of an inhomogeneous azeotrope in mixtures where a homogeneous one should have been predicted is also observed, such as in the acetone-water $\left(\mathrm{BAC}_{8}\right)$ (Figure $6 \mathrm{a}$ ) mixture. This is also the case for mixtures belonging to the $\mathrm{BAC}_{9}$ group, which are composed of two self-associating components. For example, the PC-SAFT EoS predicts with high accuracy the VLE of the ethanol-water $\left(\right.$ BAC $\left._{9}\right)$ mixture (Figure $7 \mathrm{~d}$ ), which forms homogeneous azeotropes at various temperatures, while the model consistently overpredicts the azeotropic pressure of the water-propylene glycol monomethyl ether mixture (Figure $7 \mathrm{~b})$.

Moreover, the deviations from ideality that the various mixtures exhibit do not seem to correlate directly with the expected accuracy of the results because better or worse predictions are observed in both ideal or nearly ideal systems and mixtures in which strong deviations from ideality are 
exhibited. As shown in Figure 5c, PC-SAFT predicts positive deviations from ideality for the chloroform-1-propanol mixture $\left(\mathrm{BAC}_{7}\right)$, and the VLE results are very accurate for the isotherm at $328.15 \mathrm{~K}$. However, for the trichloroethylene-2-methoxyethanol mixture $\left(\mathrm{BAC}_{7}\right.$ ) at $341.01 \mathrm{~K}$ (Figure $5 \mathrm{~d}$ ), the model predicts negative deviations from ideality that do not conform to the experimentally observed behavior. It has to be noted though that based on the assessment of Jaubert et al. ${ }^{8}$ for the origin of non-ideality in the mixtures of the database, deviations from ideality for the chloroform-1-propanol $\left(\mathrm{BAC}_{7}\right)$ mixture originate from enthalpic and entropic causes, while for the trichloroethylene-2-methoxyethanol mixture $\left(\mathrm{BAC}_{7}\right)$ they originate only from entropic.

Considerable improvement in the performance of the EoS is expected by incorporating a non-zero BIP in the combining rules for the dispersion energy of the model. To showcase this, representative calculations were performed for the carbon dioxide-ethane mixture with $k_{i j}=0.1125$ at various temperatures. The results are summarized in Figure 9, together with the predictions of PC-SAFT $\left(k_{i j}=0\right)$ for this mixture at the same temperatures. As also shown by Jaubert and Privat, ${ }^{32}$ the PCSAFT EoS fails to qualitatively reproduce the behavior of the mixture without the use of a BIP. Excellent correlation of the experimental data is achieved however with a temperatureindependent $k_{i j}$ parameter. Similar improvement is also observed for the mixtures presented in Figure 1 (calculations with fitted $k_{i j}$ parameters are represented by dashed lines), when a temperature-independent BIP is fitted to the available experimental data. Regression of BIPs for the PC-SAFT EoS and grading of the model using the same methodology applied in this work are ongoing and will be the scope of a future publication.

\section{CONCLUSIONS}

The PC-SAFT EoS was applied in this work without the use of any BIPs, as well as no induced association scheme for mixtures of a self-associating and a non-self-associating compound. The performance of the model was compared against the experimental data of the benchmark database, published by Jaubert et al. ${ }^{8}$ The EoS was graded using the proposed methodology, and the resulting marks as well as the behavior of the model for the various groups of mixtures were discussed and analyzed.

The PC-SAFT EoS, as implemented in this work, received a low overall score of 5.1/20. However, important strengths of the $\mathrm{EoS}$, such as the very good performance for $\mathrm{BAC}_{5}$ mixtures (taking into account that calculations are purely predictive), which are considered very difficult to model, were shown, as well as the importance of the association term in the general performance of the model. The significance of the association term is clearly supported by taking into account that Mark $_{\mathrm{NA}}=$ $\mathrm{Mark}_{\mathrm{CA}+\mathrm{SA}}$. Considerable weakness seems to be the case of mixtures in which only cross-association takes place $\left(\mathrm{BAC}_{6}\right)$, as demonstrated by the very low mark $(1.8 / 20)$ received. Another drawback is the inability to reproduce even qualitatively the azeotropic behavior of non-associating mixtures $\left(\mathrm{BAC}_{1}-\mathrm{BAC}_{4}\right)$, which is clearly shown by the very large percent of "out of model" data points in this case. Finally, a significant number of "out of model" data points were also observed for three-phase equilibrium data $(66.6 \%)$, which highlights the difficulty in reproducing simultaneously the VLE and LLE behavior.

In the context of benchmarking thermodynamic models, using the database proposed by Jaubert et al., ${ }^{8}$ we propose as future work the use of an induced association scheme in the PC-
SAFT EoS for mixtures in which a self-associating compound is mixed with a non-self-associating one that has the potential to cross-associate (some mixtures in $\mathrm{BAC}_{5}, \mathrm{BAC}_{6}, \mathrm{BAC}_{7}$, and $\mathrm{BAC}_{8}$ groups). In this way, the effect of solvation can be extensively evaluated by directly comparing with the marks reported in this work. Finally, regression of BIPs for all available mixtures in the database and comparing with the purely predictive calculations reported in this work are required to assess the potential of the PC-SAFT EoS.

\section{ASSOCIATED CONTENT}

\section{SI Supporting Information}

The Supporting Information is available free of charge at https://pubs.acs.org/doi/10.1021/acs.iecr.1c01234.

Pure component parameters for the PC-SAFT EoS and specified and calculated variables for the different properties included in the database (PDF)

\section{AUTHOR INFORMATION}

\section{Corresponding Authors}

Jean-Noël Jaubert - École Nationale Supérieure des Industries Chimiques, Laboratoire Réactions et Génie des Procédés (UMR CNRS 7274), Université de Lorraine, 54000 Nancy, France; 이잉.org/0000-0001-7831-5684; Email: jeannoel.jaubert@univ-lorraine.fr

Ioannis G. Economou - National Center for Scientific Research "Demokritos", Molecular Thermodynamics and Modelling of Materials Laboratory, Institute of Nanoscience and Nanotechnology, GR 15310 Aghia Paraskevi Attikis, Greece; Chemical Engineering Program, Texas A\&M University at Qatar, 23874 Doha, Qatar; (1) orcid.org/0000-0002-24096831; Email: ioannis.economou@qatar.tamu.edu

\section{Authors}

Ilias K. Nikolaidis - National Center for Scientific Research "Demokritos", Molecular Thermodynamics and Modelling of Materials Laboratory, Institute of Nanoscience and Nanotechnology, GR 15310 Aghia Paraskevi Attikis, Greece; (1) orcid.org/0000-0002-4816-4616

Romain Privat - Ecole Nationale Supérieure des Industries Chimiques, Laboratoire Réactions et Génie des Procédés (UMR CNRS 7274), Université de Lorraine, 54000 Nancy, France; orcid.org/0000-0001-6174-9160

Complete contact information is available at:

https://pubs.acs.org/10.1021/acs.iecr.1c01234

\section{Notes}

The authors declare no competing financial interest.

\section{ACKNOWLEDGMENTS}

NCSR “Demokritos" acknowledges financial support from CNRS, France.

\section{REFERENCES}

(1) Bell, I. H.; Messerly, R.; Thol, M.; Costigliola, L.; Dyre, J. C. Modified Entropy Scaling of the Transport Properties of the LennardJones Fluid. J. Phys. Chem. B. 2019, 123, 6345-6363.

(2) Lötgering-Lin, O.; Gross, J. Group Contribution Method for Viscosities Based on Entropy Scaling Using the Perturbed-Chain Polar Statistical Associating Fluid Theory. Ind. Eng. Chem. Res. 2015, 54, $7942-7952$. 
(3) Quiñones-Cisneros, S. E.; Deiters, U. K. Generalization of the Friction Theory for Viscosity Modeling. J. Phys. Chem. B. 2006, 110, 12820-12834.

(4) Quiñones-Cisneros, S. E.; Zéberg-Mikkelsen, C. K.; Fernández, J.; García, J. General friction theory viscosity model for the PC-SAFT equation of state. AIChE J. 2006, 52, 1600-1610.

(5) Chen, C.-C.; Mathias, P. M. Applied thermodynamics for process modeling. AIChE J. 2002, 48, 194-200.

(6) Hendriks, E.; Kontogeorgis, G. M.; Dohrn, R.; de Hemptinne, J.C.; Economou, I. G.; Žilnik, L. F.; Vesovic, V. Industrial Requirements for Thermodynamics and Transport Properties. Ind. Eng. Chem. Res. 2010, 49, 11131-11141.

(7) Kontogeorgis, G. M.; Dohrn, R.; Economou, I. G.; de Hemptinne, J.-C.; ten Kate, A.; Kuitunen, S.; Mooijer, M.; Žilnik, L. F.; Vesovic, V. Industrial Requirements for Thermodynamic and Transport Properties: 2020. Ind. Eng. Chem. Res. 2021, 60, 4987-5013.

(8) Jaubert, J.-N.; Le Guennec, Y.; Piña-Martinez, A.; Ramirez-Velez, N.; Lasala, S.; Schmid, B.; Nikolaidis, I. K.; Economou, I. G.; Privat, R. Benchmark Database Containing Binary-System-High-Quality-Certified Data for Cross-Comparing Thermodynamic Models and Assessing Their Accuracy. Ind. Eng. Chem. Res. 2020, 59, 14981-15027.

(9) Peng, D.-Y.; Robinson, D. B. A New Two-Constant Equation of State. Ind. Eng. Chem. Fundam. 1976, 15, 59-64.

(10) Jaubert, J.-N.; Mutelet, F. VLE predictions with the PengRobinson equation of state and temperature dependent kij calculated through a group contribution method. Fluid Phase Equilib. 2004, 224, 285-304.

(11) Gross, J.; Sadowski, G. Perturbed-Chain SAFT: An Equation of State Based on a Perturbation Theory for Chain Molecules. Ind. Eng. Chem. Res. 2001, 40, 1244-1260.

(12) Gross, J.; Sadowski, G. Application of the Perturbed-Chain SAFT Equation of State to Associating Systems. Ind. Eng. Chem. Res. 2002, 41, $5510-5515$.

(13) Chapman, W. G.; Gubbins, K. E.; Jackson, G.; Radosz, M. New reference equation of state for associating liquids. Ind. Eng. Chem. Res. 1990, 29, 1709-1721.

(14) Chapman, W. G.; Jackson, G.; Gubbins, K. E. Phase equilibria of associating fluids: Chain molecules with multiple bonding sites. Mol. Phys. 1988, 65, 1057-1079.

(15) Jackson, G.; Chapman, W. G.; Gubbins, K. E. Phase equilibria of associating fluids: Spherical molecules with multiple bonding sites. Mol. Phys. 1988, 65, 1-31.

(16) Wertheim, M. S. Fluids with highly directional attractive forces. I. Statistical thermodynamics. J. Statist. Phys. 1984, 35, 19-34.

(17) Wertheim, M. S. Fluids with highly directional attractive forces. II. Thermodynamic perturbation theory and integral equations. J. Statist. Phys. 1984, 35, 35-47.

(18) Wertheim, M. S. Fluids with highly directional attractive forces. III. Multiple attraction sites. J. Statist. Phys. 1986, 42, 459-476.

(19) Wertheim, M. S. Fluids with highly directional attractive forces. IV. Equilibrium polymerization. J. Statist. Phys. 1986, 42, 477-492.

(20) Chen, S. S.; Kreglewski, A. Applications of the Augmented van der Waals Theory of Fluids.: I. Pure Fluids. Ber. Bunsen. Phys. Chem 1977, 81, 1048-1052.

(21) Huang, S. H.; Radosz, M. Equation of state for small, large, polydisperse, and associating molecules. Ind. Eng. Chem. Res. 1990, 29, 2284-2294.

(22) Huang, S. H.; Radosz, M. Equation of state for small, large, polydisperse, and associating molecules: extension to fluid mixtures. Ind. Eng. Chem. Res. 1991, 30, 1994-2005.

(23) Moine, E.; Piña-Martinez, A.; Jaubert, J.-N.; Sirjean, B.; Privat, R. I-PC-SAFT: An Industrialized Version of the Volume-Translated PCSAFT Equation of State for Pure Components, Resulting from Experience Acquired All through the Years on the Parameterization of SAFT-Type and Cubic Models. Ind. Eng. Chem. Res. 2019, 58, 20815-20827.

(24) Topliss, R. J.; Dimitrelis, D.; Prausnitz, J. M. Computational aspects of a non-cubic equation of state for phase-equilibrium calculations Effect of density-dependent mixing rules. Comput. Chem. Eng. 1988, 12, 483-489.

(25) Michelsen, M. L. The isothermal flash problem Part I. Stability. Fluid Phase Equilib. 1982, 9, 1-19.

(26) Michelsen, M. L. The isothermal flash problem. Part II. Phasesplit calculation. Fluid Phase Equilib. 1982, 9, 21-40.

(27) Privat, R.; Jaubert, J.-N. Discussion around the paradigm of ideal mixtures with emphasis on the definition of the property changes on mixing. Chem. Eng. Sci. 2012, 82, 319-333.

(28) Qian, J.-W.; Privat, R.; Jaubert, J.-N.; Duchet-Suchaux, P. Enthalpy and Heat Capacity Changes on Mixing: Fundamental Aspects and Prediction by Means of the PPR78 Cubic Equation of State. Energy Fuel 2013, 27, 7150-7178.

(29) Michelsen, M. L.; Mollerup, J. M., Thermodynamic Models: Fundamentals \& Computational Aspects. 2nd ed.; Tie-Line Publications: Denmark, 2007.

(30) Konynenburg, P. H. V.; Scott, R. L. Critical Lines and Phase Equilibria in Binary Van Der Waals Mixtures. Philos. Trans. R. Soc. Lond. A 1980, 298, 495-540.

(31) Privat, R.; Jaubert, J.-N. Classification of global fluid-phase equilibrium behaviors in binary systems. Chem. Eng. Res. Des. 2013, 91, 1807-1839.

(32) Jaubert, J.-N.; Privat, R. SAFT and cubic EoS: Type of deviation from ideality naturally predicted in the absence of BIPs Application to the modelling of athermal mixtures. Fluid Phase Equilibria 2021, 533, No. 112924. 